\title{
用新工科理念做强做优盐湖化工特色专业
}

赵启文*，成春春

青海大学化工学院, 西宁 810016

\begin{abstract}
摘要: 为了做强做优盐湖化工特色专业, 更好地服务地方经济建设, 我们应用新工科的理念对化工专业特色方向建设进 行了系统的设计与改革, 通过举办 “卓越工程师” 班, 积极推进盐湖化工对接产业发展的新需求, 建立了多学科交叉完 善课程体系, 通过更新教学内容、推进产学研用合作、强化创新和工程实践能力培养等, 积极探索新工科人才培养, 为 未来建设盐湖科学与工程专业积累了经验, 奠定了基础。
\end{abstract}

关键词: 新工科; 盐湖化工; 多学科交叉; 校企合作

中图分类号: G642.0; O6

\section{Improve the Specialty of Salt Lake Chemical Industry Based on the Concepts of Emerging Engineering Education}

\author{
Qiwen Zhao *, Chunchun Cheng \\ College of Chemical Engineering, Qinghai University, Xining 810016, P. R. China.
}

\begin{abstract}
In order to better serve the local economic construction, the specialty of Salt Lake chemical industry is strengthened and optimized based on the concept of emerging engineering education (3E). The education reform has been carried out actively so as to meet the new needs of industrial development. The improvement of curriculum system was made by enhancing the multi-discipline education, updating the teaching contents, setting up school enterprise cooperation for teaching, research and application with strengthening innovation and engineering practice ability training. The reform has achieved good results and laid solid foundation for the future development of a new $3 E$ major of Science and Technology of Salt Lake.
\end{abstract}

Key Words: Emerging engineering education; Salt Lake chemical industry; Interdisciplinary;

School-enterprise cooperation

\section{1 引言}

青海全省矿产资源潜在价值共有 104.56 万亿元, 其中盐湖矿产潜在总值合计为 99.15 万亿元, 占全省矿产资源潜在总值的 $94.83 \%{ }^{[1]}$ 。资源禀赋决定了青海地方经济发展要依托盐湖资源。青海高 度重视盐湖资源综合利用, 已建成国内重要的钾肥生产基地、纯碱生产基地、镁产业基地和锂产业 基地。目前青海盐湖资源主要以开发钾、钠、锂、镁、硼等潜在价值较大的资源为主, 以保护生态、 节能减排、发展循环经济为导向 ${ }^{[2]}$ 。如中国最大的盐湖——察尔汗盐湖, 资源主要以卤水形式存在, 综合采用不同化工分离方法分级分批从卤水中提取不同产品, 一般先通过盐田滩晒提取氯化钠、再

收稿: 2020-06-02; 录用: 2020-07-13; 网络发表: 2020-07-20

“通讯作者, Email: zhqwqd@126.com

基金资助: 教育部首批 “新工科” 研究与实践项目; 青海大学教育教学研究项目(JY201804) 
通过浮选提取氯化钾, 然后根据不同产品选择合适的分离方法提取美、硼, 最后提取锂。青海除盐 湖外, 还有较丰富的天然气、煤、石油资源, 为减少化工产业废弃物排放, 资源充分利用, 积极将 以盐、煤、天然气、石油等为原料的化工产业交叉融合, 延长产业链, 形成了一系列具有区域资源 特色的高附加值产品。目前工业发展的趋势之一是传统产业在不断交叉融合, 不断推出性能更好的 新产品, 这要求高校对传统专业进行改造升级, 方法之一就是依据产业发展需求, 将相关专业交叉 融合建设新工科专业，培养一专多能、满足产业不断转型升级所需的复合型人才 ${ }^{[3]}$ 。

青海大学化工类专业办学 42 年来, 始终以服务地方经济建设为己任, 围绕盐湖化工建特色专 业, 累计为社会输送了 4000 余名毕业生, 他们中的很多人已经成为推动青海化工行业发展的技术骨 干。2018 年我校获批了教育部新工科项目 “盐湖科学与工程专业建设探索及实践”, 借助项目实施, 我们认识到新工科建设要坚持问题导向, 做到六问: 问产业需求建专业, 问技术发展改内容, 问学 校主体推改革, 问学生志趣变方法, 问内外资源创条件, 问国际前沿立标准 ${ }^{[4]}$ 。新工科的主要内涵为

“五个新” , 即工程教育的新理念、学科专业的新结构、人才培养的新模式、教育教学的新质量、 分类发展的新体系 ${ }^{[5]}$ 。基于对新工科的认识, 我们积极用新工科的理念升级改造化学工程与工艺专 业, 重点提升盐湖化工 “卓越工程师” 班的培养水平, 做强做优盐湖化工特色, 取得了一定的成效。

\section{2 我校盐湖化工特色专业建设遇到的问题}

新工科项目实施过程中, 我们深入格尔木、德令哈、大柴旦等地的主要盐湖化工企业, 以及在 青海的有关化工科研院所进行了调研。用人单位对青海大学化工专业毕业生的主要评价为: 基础扎 实、责任心强、工作认真、踏实肯干, 是企业的技术骨干。在过去盐湖化工特色专业建设中, 我们 也遇到了不少问题, 结合本次调研结果总结归纳为 4 个主要问题。(1) 培养的人才与市场需求有差 距。学生工程设计、绘制和阅读工程图纸能力偏弱, 部分盐化工企业缺少掌握水文地质、采矿、盐 田工艺、化学工程、材料科学、信息技术、环境工程等交叉知识的复合型人才。(2) 学生对盐湖化工 兴趣不高。我校每年招生时, 化工专业按化工与制药大类招生, 基础课阶段统一培养, 专业课学习 前进行专业分流, 学生自愿选择中出现了报盐湖化工 “卓越工程师” 班学生相对较少的问题。经调 查主要原因有 2 个方面: 一是盐湖化工企业大多在湖区, 一般地上不长草、天上无飞鸟, 工作地点 偏远艰苦, 学生不愿意到盐湖化工企业就业; 二是盐湖化工产业主要分布在国内中西部, 学生担心 学习盐湖化工专业会影响考研, 以及影响将来到东南部经济发达地区就业。(3) 企业、科研院所参与 学校人才培养的积极性不高。化工生产中经常会涉及一些有毒有害、易燃易爆的原料、中间物料或 产品, 如果日常管理或操作不当容易发生安全事故, 因此国家对化工行业安全生产要求越来越严。 化工企业为确保不出事故、安全生产, 往往不愿意接受高校实习生。科研院所研究人员需要完成的 任务量较大，课题申报存在竞争，与高校合作承担科研项目的积极性不高。青海为经济欠发达地区， 化工企业数量相对较少、规模较小、多处于发展阶段, 参与高校人才培养的积极性不高。(4) 教学内 容与市场需求之间存在脱节。随着人们日益增长的物质和文化生活的需要, 工业产品的更新换代速 度不断加快, 企业普遍加大研发和使用新技术、新工艺的力度, 新产品不断涌现, 而高校传统工科 专业教学内容、知识更新的速度相对较慢, 或多或少与市场需求存在脱节的现象。

过去, 我们制定人才培养方案过多强调专业理论的系统性与知识的完整性, 基础课、实验课教 学内容往往多年不变, 专业课教学内容随产业发展有少量变化, 但更新速度普遍不如企业生产技术 更新速度快。如毕业设计(论文), 我校能源化学工程、化学工程与工艺、盐湖化工 “卓越工程师” 班 等化工类专业每届毕业学生近 200 名, 学校要求一人一题、要结合生产实践完成设计, 最终的设计 说明书(论文)要通过知网查重, 教师和学生都感到压力较大。首先选择题目较困难, 大多新产品没有 设计手册等资料可供参考。其次学生边找工作边进行毕业设计, 投入的时间精力不足, 为此, 教师 往往选取一些老化工产品生产装置题目让学生进行模拟设计训练, 有设计手册、工程图纸等资料可 供参考, 学生只要努力在有限的时间内能够完成设计任务, 能使学生掌握化工工艺设计的基本原理 
和方法, 但与就业后企业的实际生产有一定的差距。另外, 重理论知识的传授, 轻工程实践和动手 能力的培养在一定范围内仍然存在。

\section{3 用新工科理念提升盐湖化工特色专业的探索}

\section{1 设置盐湖科学与工程专业的必要性和建设计划}

调研结果显示, 目前企业普遍缺乏既掌握盐湖地质、采矿、生态环境等方面的科学知识, 又具 备盐湖化学工程实践能力的复合型人才。设置盐湖科学与工程专业的目的, 是建立符合新工科理念, 符合国家对盐湖资源综合利用、循环利用的开发战略, 符合青海省区域经济发展中重点发展盐化工 的战略, 符合专业设置从学科导向转向产业需求导向的发展趋势的新专业, 能有效改变目前存在的 专业设置与市场需求脱节的问题。另一方面, 青海是盐湖资源大省, 青海大学作为地方高校建设盐 湖科学与工程专业, 能更好地发挥办学特色和优势, 能更好地对区域经济发展和盐湖优势产业转型 升级发挥支撑作用。

经组织专家研讨, 我校的盐湖科学与工程专业计划分两步建设。第一步是用新工科的理念改造 升级盐湖化工 “卓越工程师” 培养计划, 改造升级化学工程与工艺专业, 积累多学科交叉办新工科 专业的经验; 第二步是申报建设盐湖科学与工程新工科专业。目前我们已编制了盐湖科学与工程专 业设置论证报告、课程体系、本科培养方案、指导性教学计划、主要专业课程教学大纲、考试大纲, 为下一步建设该专业奠定了基础。

\section{2 改革招生模式}

从 2018 年开始, 我校改革化工专业先按大类招生培养后分专业培养的模式, 将盐湖化工 “卓越 工程师” 招生计划单列, 每年招一个班, 在招生简章中明确该班主要面向盐湖地区就业。在培养方 案中加强实践性教学环节, 突出强化学生的工程观念、工程实践能力、工程设计能力、工程制图能 力、计算机应用和创新实践能力的培养。实施两年的效果表明, 本项改革举措有利于保证生源质量, 能够招到真正喜欢盐湖化工的青年学子，有利于培养下得去、用得上、留得住的工程技术人才。

\section{3 积极与企业、科研院所合作，加大开放办学}

我们积极深入企业、科研院所寻求优势互补的合作途径, 与多家企业签订了产学研合作协议, 在企业搭建实践教学平台、为学生实习服务, 安排专家教授到企业开展学术讲座、职工培训, 学校 提供实验室、科研仪器设备, 企业提供启动资金, 共同建设技术研发中心, 共同承担企业技术改造、 新产品研发, 以及共同申报各类科研项目。聘请企业优秀工程技术人员到学校做学术报告, 参与学 校人才培养方案制定、课程教学, 共同指导本科毕业论文和硕士研究生学位论文。安排青年教师到 企业挂职锻炼, 有些近几年入职的博士教师参加企业工程实践后很有感触, 课堂上给学生讲解了几 年的塔器、反应器, 第一次在生产现场看到工业化的大装置, 理解更加深刻。部分学生通过参与实 习、科研项目实现了课堂与工作的无缝对接, 在学校练就了一身解决实际问题的本领。下一步我们 打算与骨干盐化工企业合作, 在学校建设主要盐化工产品生产工艺仿真实训平台, 为学生提供实习 教学的同时为企业提供职工培训服务。

\section{4 完善课程体系, 突出培养创新和工程实践能力}

以提升学生的创新精神和工程实践能力为目标, 完善课程体系, 一方面将当前青海主要化工产 品相关知识、工程实践知识、产业发展前沿知识引入到课程体系中, 如培养方案修订中增加了 ASPEN (Advanced System for Process Engineering)与过程模拟、工程技术经济评价、仿真实训、绿色化工导 论等课程; 另一方面不断加强基础课实验、专业实验、课程设计、认识实习、生产实习、毕业设计 (论文)等实践教学, 如专业实验中增加设备台套数, 更新实验教学内容, 开出选做实验、开放实验室 预约做实验, 每组人数不超过 4 人。延长 “卓越工程师” 班生产实习时间, 师生住宿在企业生产一 线, 上午到生产现场了解工艺流程、设备结构和工艺参数, 下午由教师和企业工程技术人员讲课, 晚上组织讨论, 将 4 门主要专业课程安排在企业实习期间讲授, 第一天书本上学习的理论知识第二 
天在生产现场就能得到见证, 取得良好的学习效果。增加了创新创业学分, 将毕业总学分由 170 减 到 160 , 为学生留出了开展创新创业活动的时间; 约有 $40 \%$ 的学生通过承担中科院大学生创新实践 计划项目、校大学生科技创新基金项目, 以及参与教师、科研院所专家和就业单位的科研项目完成 毕业论文。

\section{5 对接市场需求、更新教学内容}

我校化工专业建设着力打造盐化工特色, 编辑出版的《盐化工工艺学》为高等教育 “十三五” 规划教材, 目前正在编辑含有多个盐化工实验的《化工专业实验》教材。在原先开设盐化工工艺学、 水盐体系相图课程的基础上, 根据青海盐湖化工产业发展的新进展, 增加了化工结晶过程原理及应 用、盐矿物鉴定概论、卤水资源及利用等盐化工特色课程。下一步, 我们计划增加有关盐湖资源开 发中美、锂提取及深加工, 下游新材料产品的生产工艺, 以及循环利用等内容的课程, 努力使教学 内容与市场需求更好地衔接。

\section{6 多学科交叉, 增强实用性}

随着青海盐湖资源开发的不断深入，产业交叉融合，产品种类增多，企业对既掌握采矿知识、 车间加工工艺, 又了解生态保护及环境工程知识的复合型人才的需求越来越大。为此, 我们提出在 盐湖化工 “卓越工程师” 培养计划中增加结晶学与矿物学、环境生态学、工程地质及水文地质等选 修课程, 充分利用青海大学现有相关工科专业的师资和教学条件, 探索多学科交叉培养掌握化工、 地质、能源、信息、材料、生态及环境工程等知识的复合型人才, 努力做到学有专攻, 一专多能, 增强实用性，以便更好地满足柴达木盆地盐湖资源开发利用的新需求。

为了更好地培养复合型人才, 我们计划在盐湖科学与工程专业采用 “平台 + 模块” 的课程体系 结构, 在公共基础课、学科平台课、专业基础课等平台课程与化学工程与工艺专业相同的前提下, 在专业课中设置 3 个课程模块, 每个模块包含 3 门课程, 其中模块 1 包括环境生态学、结晶学与矿 物学、工程地质及水文地质; 模块 2 包括水盐体系相图、盐化工工艺学、化工结晶过程原理及应用; 模块 3 包括绿色化学原理及应用、材料科学基础、循环经济。模块 1 偏向盐湖资源开发的初期采矿、 盐田滩晒制取矿料过程的知识; 模块 2 偏向盐湖资源开发中期, 对含钾、钠、镁、锂等离子的盐化 工初级产品加工过程的知识; 模块 3 偏向盐湖资源开发后期, 以初级产品为原料进一步生产相关功 能材料等高附加值产品的知识。要求学生依据本人兴趣至少选修一个课程模块。

\section{4 结语}

新工科项目实施两年来, 我们进行了积极的探索, 用新工科理念提升我校盐湖化工特色专业建 设水平, 努力对接产业发展的新需求, 通过多学科交叉、更新教学内容、完善课程体系、校企产学 研用合作、强化创新和工程实践能力培养等措施不断提高盐湖化工 “卓越工程师” 班的人才培养质 量。学生参加国内化工类学科竞赛，2018-2019 年获得第十二届全国大学生化工设计竞赛二等奖、 第二届全国 “互联网 + 化学反应” 课模设计大赛三等奖、第十三届全国大学生化工设计竞赛二等 奖、第一届全国大学生化学实验创新设计竞赛二等奖等, 取得了良好的育人效果, 为未来建设盐湖 科学与工程专业奠定了基础, 积累了经验。

\section{参 考 文 献}

[1] 青海盐湖矿产潜在总值 99.15 万亿元. [2020-05-06]. http://www.chinanews.com/ny/2017/01-8/8128420.shtml.

[2] 青海省“十三五”工业和信息化发展规划. [2020-05-06]. http://www.qhec.gov.cn/html/58/2929.html.

[3] 李正良, 廖瑞金, 董凌燕. 高等工程教育研究, 2018, No. 2, 20.

[4] 张大良. 中国大学教育, 2017, No. 4, 4 .

[5] 索贵涁. 教育教学论坛, 2018, No. 43, 209. 